\section{Don't blame it on Fluorine: Low F concentrations in Deccan Traps magmas straddling the extinction interval estimated from in situ analyses on clinopyroxene}

DON R BAKER ${ }^{1}$, SARA CALLEGARO ${ }^{2}$ PAUL RENNE $^{3}$ LEONE MELLUSO ${ }^{4}$, ANGELO DE MIN ${ }^{5}$, MARTIN WHITEHOUSE $^{6}$ AND ANDREA MARZOLI $^{7}$

${ }^{1}$ McGill University

${ }^{2}$ Centre for Earth Evolution and Dynamics (CEED), University of Oslo

${ }^{3}$ Berkeley Geochronology Center and University of California, Berkeley

${ }^{4}$ University of Naples- Federico II

${ }^{5}$ University of Trieste

${ }^{6}$ Swedish Museum of Natural History

${ }^{7}$ University of Padova

Presenting Author: don.baker@mcgill.ca

Clinopyroxenes from $\mathrm{a} \sim 3500 \mathrm{~m}$ thick composite Western Ghats section of the Deccan Traps were analyzed for fluorine using the NORDSIM ion microprobe. These results were combined with newly determined partition coefficients [1] to estimate fluorine concentrations in coexisting melts. Concentrations of $\mathrm{F}$ in the melts for each formation are variable, typically from $\sim 0.03$ to $\sim 0.15$ wt. $\%$, although one melt appears to have contained more than $0.4 \mathrm{wt} . \% \mathrm{~F}$ (see figure). Both the maximum and the mean fluorine concentrations for each formation display a zig-zag pattern through the section, but a broad minimum in concentration is seen near the CretaceousPaleogene boundary (K-Pg) [2, 3]. Because F remains highly soluble in silicate melts even during degassing at low pressures, the large variations are unlikely due to volatile loss, and the low crystallinity of the rocks $(<15 \%)$, their similar $\mathrm{MgO}$ concentrations $(5-8 \mathrm{wt} \%)$, and the small range of clinopyroxene compositions argue against fractionation enrichment as an explanation for the variations. Instead, we attribute these variations in melt $\mathrm{F}$ concentrations to changes in the magmatic plumbing system that fed the lava flows. The low $F$ concentrations near the K-Pg combined with the volumes of each formation suggest that the outgassing of $\mathrm{F}$ alone from the Deccan was not a significant factor in the K-Pg extinction event. However, the $\mathrm{F}$ released from the Deccan Traps eruption in combination with other mechanisms may have contributed to global environmental perturbations from shortly before the K-Pg through post-extinction recovery.

1. Baker, D.R. et al. (in press) Fluorine partitioning between quadrilateral clinopyroxenes and melt. American Mineralogist. https://doi.org/10.2138/am-2021-7868

2. Schoene, B. et al. (2019) U-Pb constraints on pulsed eruption of the Deccan Traps across the end-Cretaceous mass extinction. Science, 363, 862-866.

3. Sprain, C.J. et al. (2019) The eruptive tempo of Deccan volcanism in relation to the Cretaceous-Paleogene boundary. Science, 363, 866-870.

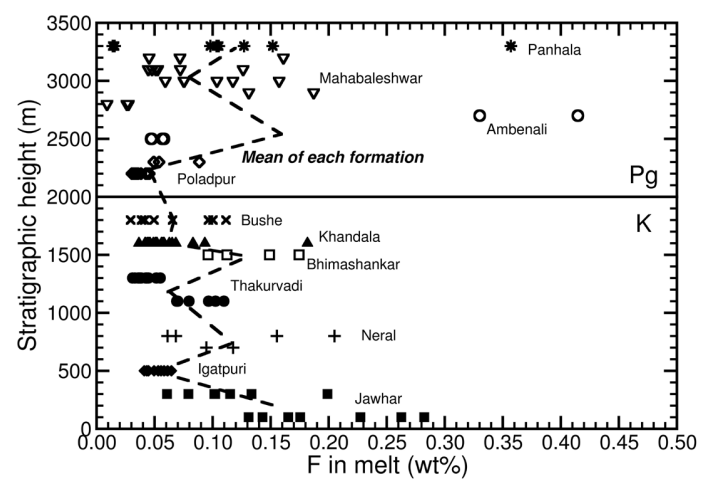

